\title{
UTILIZAÇÃO DO NITROGÊNIO DA PALHA DE MILHO E DE ADUBOS VERDES PELA CULTURA DO MILHO ${ }^{(1)}$
}

\author{
Edson Cabral da Silva ${ }^{(2)}$, Takashi Muraoka ${ }^{(3)}$, Salatiér Buzetti( ${ }^{(4)}$, Freddy Sinencio \\ Contreras Espinal ${ }^{(5)}$ \& Paulo César Ocheuze Trivelin ${ }^{(3)}$
}

\begin{abstract}
RESUMO
A qualidade dos resíduos vegetais de culturas comerciais e adubos verdes influencia a taxa de mineralização/imobilização de $\mathrm{N}$ e o respectivo aproveitamento desse nutriente pelas subseqüentes culturas. Com o objetivo de avaliar a utilização do $\mathrm{N}$ mineralizado da parte aérea e do sistema radicular da crotalária (Crotalaria juncea) e milheto (Pennisetum americanum) e da palha de milho, marcados com ${ }^{15} \mathrm{~N}$, realizou-se um estudo, em casa de vegetação, no Centro de Energia Nuclear na Agricultura - CENA/USP, Piracicaba (SP), em vasos com $5 \mathrm{~kg}$ de solo de um Latossolo Vermelho distroférrico. Foram utilizados seis tratamentos e quatro repetições, dispostos num delineamento inteiramente casualizado, compreendendo: $T_{1}=$ palha de milho- ${ }^{15} \mathrm{~N}$ (parte aérea, exceto os grãos) $\left(80 \mathrm{mg} \mathrm{kg}^{-1}\right.$ de $\mathrm{N}$ no solo); $\mathrm{T}_{2}=$ raiz de milheto- ${ }^{15} \mathrm{~N}$ (30 $\mathrm{mg} \mathrm{kg}^{-1}$ de $\mathrm{N}$ no solo); $\mathrm{T}_{3}$ = parte aérea de milheto-- ${ }^{15} \mathrm{~N}$ (80 $\mathrm{mg} \mathrm{kg}^{-1}$ de $\mathrm{N}$ no solo); $\mathrm{T}_{4}=$ raiz de crotalária- ${ }^{15} \mathrm{~N}\left(30 \mathrm{mg} \mathrm{kg}^{-1} \mathrm{de} \mathrm{N} \mathrm{no}\right.$ solo); $\mathrm{T}_{5}=$ parte aérea de crotalária- ${ }^{15} \mathrm{~N}\left(80 \mathrm{mg} \mathrm{kg}^{-1} \mathrm{de} \mathrm{N}\right.$ no solo $)$ e $\mathrm{T}_{6}=$ tratamento sem adição de fonte orgânica de $\mathrm{N}$. Para os tratamentos que receberam raiz marcada $\operatorname{com}^{15} \mathrm{~N}$, adicionou-se parte aérea sem marcação isotópica na mesma quantidade que naqueles que receberam parte aérea marcada, e vice-versa. As raízes foram incorporadas ao solo e a parte aérea adicionada sobre a superfície. Para avaliar absorção de $\mathrm{N}$ da palha de milho- ${ }^{15} \mathrm{~N}\left(7,35 \mathrm{Mg} \mathrm{ha}^{-1}\right.$, equivalente a $\left.56 \mathrm{~kg} \mathrm{ha}^{-1} \mathrm{de} \mathrm{N}\right)$ pela cultura do milho, realizou-se também um experimento de campo, na mesma área em que foi coletado solo para o experimento de casa de vegetação. A quantidade de $\mathrm{N}$ no milho proveniente da crotalária $\left(111,80 \mathrm{mg}^{\mathrm{vaso}} \mathrm{va}^{-1} \mathrm{~N}\right)$ foi superior à do milheto $\left(30,98 \mathrm{mg} \mathrm{vaso}^{-1} \mathrm{~N}\right)$, que foi superior à da palha de milho $\left(11,80 \mathrm{mg} \mathrm{vaso}^{-1} \mathrm{~N}\right)$.
\end{abstract}

\footnotetext{
(1) Projeto financiado pela FAPESP e IAEA. Trabalho apresentado no XXXI Congresso Brasileiro de Ciência do Solo, 2007 (Gramado, RS).

(2) Pós-doutorando da Universidade de São Paulo - CENA/USP. Rua Adolpho Schievano, 350, Vila Rezende, CEP 13405-327 Piracicaba (SP). Bolsista da FAPESP. E-mail: ecsilva@cena.usp.br

(3) Professor Associado do CENA/USP. Av. Centenário, 303, CEP 13416-970 Piracicaba (SP). Bolsistas do CNPq. E-mails: muraoka@cena.usp.br; pcotrive@cena.usp.br

(4) Professor Titular do Departamento de Fitossanidade, Engenharia Rural e Solos da FEIS/UNESP. Av. Brasil, 56, CEP 15385000 - Ilha Solteira (SP). Bolsista do CNPq. E-mail: sbuzetti@agr.feis.unesp.br

(4) Doutorando em Solos e Nutrição de Plantas, Escola Superior de Agricultura Luiz de Queiroz, Universidade de São Paulo. Av. Pádua Dias, 11 - Cx. Postal 9, CEP 13418-900 Piracicaba (SP). E-mail: fespinal@esalq.usp.br
} 
A crotalária proporcionou maior absorção de $\mathrm{N}$ e produtividade de matéria seca ao milho. $\mathrm{O}$ aproveitamento pelo milho do $\mathrm{N}$ da parte aérea da crotalária foi superior ao do $\mathrm{N}$ do sistema radicular, mas não houve diferença para o $\mathrm{N}$ do milheto. $\mathrm{A}$ absorção do $\mathrm{N}$ dos restos culturais de milho pela cultura do milho, no campo, foi de $4,1 \%$ da quantidade inicial.

Termos de indexação: Zea mays, restos culturais, milheto, crotalária, mineralização de $\mathrm{N},{ }^{15} \mathrm{~N}$.

\title{
SUMMARY: UTILIZATION OF NITROGEN FROM CORN PLANT RESIDUES AND GREEN MANURES BY CORN
}

\begin{abstract}
The quality of commercial crop residues and green manure influences the $N$ mineralization-immobilization rate and the respective use by subsequent crops. With the objective of evaluating $N$ utilization by corn of $N$ from the shoot and root system of sunnhemp (Crotolaria juncea) and millet (Pennicetum americanum) and corn straw, labeled with ${ }^{15} \mathrm{~N}$, a green house experiment was carried out at the Centro de Energia Nuclear na Agricultura (CENA/USP), Piracicaba, S. Paulo, Brazil, in $5 \mathrm{~kg}$ pots with dystroferric Red Latosol in a completely randomized design, with four replications and the following six treatments: $T_{1}={ }^{15} \mathrm{~N}$ labeled corn straw (above ground part, except grains) (80 mg kg-1 $\mathrm{N}$ in soil); $\mathrm{T}_{2}={ }^{15} \mathrm{~N}$ labeled millet root (30 $\mathrm{mg} \mathrm{kg}^{-1}$ in soil); $T_{3}={ }^{15} \mathrm{~N}$ labeled millet shoot ( $80 \mathrm{mg} \mathrm{kg}^{-1} \mathrm{~N}$ in soil); $T_{4}={ }^{15} \mathrm{~N}$ labeled sunnhemp root (30 $\mathrm{mg} \mathrm{kg}^{-1} \mathrm{~N}$ in soil); $T_{5}={ }^{15} \mathrm{~N}$ labeled sunnhemp shoot $\left(80 \mathrm{mg} \mathrm{kg}^{-1} \mathrm{~N}\right.$ in soil) and $T_{6}=$ treatment without addition of organic $N$ source. In the treatments with ${ }^{15} \mathrm{~N}$ labeled root application, unlabeled shoot at the same amount added as in those where labeled shoot was applied, and vice-versa. The roots were incorporated into the soil and shoots left on the surface. To evaluate $\mathrm{N}$ absorption from ${ }^{15} \mathrm{~N}$ corn straw $\left(7.35 \mathrm{Mg} \mathrm{ha}^{-1}\right.$, equivalent to $\left.56 \mathrm{~kg} \mathrm{ha}^{-1} \mathrm{~N}\right)$ by corn crop, a field experiment was carried out, in the same area where the soil for the green house experiment had been collected. The amount of corn $N$ derived from sunnhemp $\left(111.80 \mathrm{mg}\right.$ pot $\left.^{-1} \mathrm{~N}\right)$ was higher than from millet $\left(30.98 \mathrm{mg} \mathrm{pot}^{-1} \mathrm{~N}\right)$, which in turn higher was than from corn plant residues $\left(11.80 \mathrm{mg} \mathrm{pot}^{-1} \mathrm{~N}\right)$. Sunnhemp resulted in highest nitrogen absorption and dry matter weight of the corn crop. The corn utilized more $N$ from sunnhemp shoot than from roots, but there was no difference in $N$ derived from millet. The $N$ absorption of corn from corn straw was $4.1 \%$ of the initial amount in the field experiment.
\end{abstract}

Index terms: Zea mays, crop residues, millet, sunnhemp, nitrogen mineralization, nitrogen-15.

\section{INTRODUÇÃO}

$\mathrm{O} \mathrm{N}$ aplicado ao solo sob a forma de adubos verdes ou de fertilizantes minerais segue diferentes caminhos: uma parte é absorvida pelas plantas; outra, perdida do sistema solo-planta por processos de lixiviação, volatilização, erosão e desnitrificação (Lara Cabezas et al., 2004); e o restante permanece no solo, predominantemente na forma orgânica (Azam et al., 1985; Scivittaro et al., 2000; Amado et al., 2002). A maior parte do $\mathrm{N}$ disponível às culturas provém da interação entre a fertilização nitrogenada e a mineralização/imobilização do $\mathrm{N}$ dos resíduos de culturas e do N da matéria orgânica do solo (Sampaio $\&$ Salcedo, 1993).

O N é o nutriente absorvido em maior quantidade pelo milho e o que mais influencia a produtividade de grãos (Amado et al., 2002; Cantarella \& Duarte, 2004; Sousa \& Lobato, 2004). Normalmente, um terço do N absorvido pelo milho é restituído ao solo na forma orgânica pelos resíduos culturais (Coelho et al., 1993; Sousa \& Lobato, 2004; Silva 2006a). Além disso, a palha contribui para a mitigação da erosão do solo, aumento da infiltração e retenção de água, redução da oscilação térmica, supressão de plantas invasoras e outros, tendo sido importante para a consolidação do sistema plantio direto (SPD) no Brasil, graças à quantidade produzida, geralmente acima de $6 \mathrm{Mg} \mathrm{ha}^{-1}$, com alta relação $\mathrm{C} / \mathrm{N}$ e alto teor de lignina (Wisniewski \& Holtz, 1997).

A qualidade do resíduo vegetal, principalmente sua relação $\mathrm{C} / \mathrm{N}$ e o conteúdo de lignina e polifenóis, influencia a taxa de mineralização e o aproveitamento do $\mathrm{N}$ pelas culturas (Palm \& 
Sanchez, 1991). Dentre as espécies empregadas na adubação verde, as leguminosas destacam-se por formar associações simbióticas com bactérias fixadoras de $\mathrm{N}_{2}$ e sua baixa relação $\mathrm{C} / \mathrm{N}$, aliada à grande presença de compostos solúveis, favorece a rápida decomposição e mineralização, com expressivo aporte de $\mathrm{N}$ ao sistema solo-planta (Aita et al., 2001; Perin et al., 2004). Por outro lado, o emprego de gramíneas pode amenizar a perda de $\mathrm{N}$, mediante a reciclagem e imobilização em sua fitomassa, ao mesmo tempo e que sua baixa taxa de decomposição, favorecida pela alta relação $\mathrm{C} / \mathrm{N}$, confere cobertura mais prolongada do solo (Lara Cabezas et al., 2004; Perin et al., 2004). Aita et al. (2001), avaliando o uso de gramínea, leguminosa e pousio no inverno, evidenciaram a possibilidade de redução da quantidade de $\mathrm{N}$ mineral, aplicada ao milho cultivado após leguminosas.

Atualmente, a cultura de cobertura antecessora já constitui um dos critérios para a recomendação de adubação nitrogenada para o milho em SPD nos Estados do Rio Grande do Sul e de Santa Catarina (Amado et al., 2002). Sousa \& Lobato (2004) recomendam considerar, dentre os critérios para o cálculo da dose de $\mathrm{N}$ para o milho, um fator específico para gramíneas ou leguminosas, para estimar a contribuição do $\mathrm{N}$ mineralizado dos resíduos das três últimas culturas do verão. Esse fator deve ser multiplicado pelas suas respectivas produtividades de grãos.

Comparativamente aos fertilizantes minerais, a eficiência dos adubos verdes como fonte de $\mathrm{N}$ para as culturas tem sido baixa, raramente ultrapassando $20 \%$ no primeiro cultivo após a aplicação (Harris et al., 1994; Scivittaro et al., 2000; Silva et al., 2006a). Geralmente, a maioria dos estudos com adubos verdes não contabiliza a contribuição do $\mathrm{N}$ do sistema radicular, subestimando o seu potencial como condicionadores de nutrientes para as culturas (Azam et al., 1985). Nos estudos sobre a dinâmica do N no sistema soloplanta, muitas vezes, é difícil quantificar a recuperação do $\mathrm{N}$ e a fonte originária, o que é possível com maior exatidão quando da utilização de uma fonte marcada com ${ }^{15} \mathrm{~N}$ (Sampaio \& Salcedo et al., 1993; Ambrosano et al., 2003).

O objetivo deste trabalho foi avaliar a utilização pelo milho do $\mathrm{N}$ da parte aérea e do sistema radicular da crotalária (Crotalaria juncea) e milheto (Pennisetum americanum), em casa vegetação, e da palha de milho, em campo e casa de vegetação, marcados com ${ }^{15} \mathrm{~N}$.

\section{MATERIAL E MÉTODOS}

O estudo compreendeu duas fases. Na primeira fase, produziram-se crotalária e milheto em casa de vegetação e palha de milho (parte aérea, exceto grãos
- mistura de folha, bainha, brácteas, colmo, pendão, sabugo, cabelo e palha da espiga) no campo, com ou sem marcação isotópica com ${ }^{15} \mathrm{~N}$. Na segunda fase, as raízes de crotalária ou milheto foram incorporadas ao solo e a parte aérea de ambas as espécies e a palha de milho, adicionadas sobre a superfície do solo, cultivando-se, em seguida, milho, em casa de vegetação, no Centro de Energia Nuclear na Agricultura - CENA/USP, em Piracicaba-SP. Para avaliar a absorção do $\mathrm{N}$ da palha de milho por esta cultura, realizou-se também um ensaio de campo na fazenda experimental da Faculdade de Engenharia de Ilha Solteira - UNESP, Selvíria MS, na mesma área em que foi coletado o solo para o ensaio em casa de vegetação, classificado como Latossolo Vermelho distroférrico (LVdf) tipo A moderado argiloso (440 g $\mathrm{kg}^{-1}$ de argila) fase Cerrado tropical subcaducifólio (Embrapa, 1999).

As amostras de solo coletadas antes do inicio do experimento, na camada de 0-0,20 m, determinadas conforme métodos descritos em Raij et al. (2001), apresentaram os seguintes resultados: $\mathrm{pH}\left(\mathrm{CaCl}_{2}\right)$ : 4,8; $\mathrm{N}$ total: 1,0 $\mathrm{g} \mathrm{kg}^{-1}$; M.O.: $12,7 \mathrm{~g} \mathrm{dm}^{-3}$; P (resina): $11,7 \mathrm{mg} \mathrm{dm}{ }^{-3} ; \mathrm{Ca}^{2+}: 20,0 \mathrm{mmol}_{\mathrm{c}} \mathrm{dm}^{-3} ; \mathrm{Mg}^{2+}: 10,6$ $\mathrm{mmol}_{\mathrm{c}} \mathrm{dm}^{-3} ; \mathrm{K}: 2,0 \mathrm{mmol}_{\mathrm{c}} \mathrm{dm}^{-3} ; \mathrm{H}+\mathrm{Al}: 26,1 \mathrm{mmol}_{\mathrm{c}}$ $\mathrm{dm}^{-3}$; S: 7,5 mg dm${ }^{-3}$; SB: 32,6 mmol $_{\mathrm{c}} \mathrm{dm}^{-3}$; CTC: 58,7 mmol $_{\mathrm{c}} \mathrm{dm}^{-3}$ e saturação por bases: $55 \%$.

A produção de crotalária e de milheto (variedade ADR 500) marcados com ${ }^{15} \mathrm{~N}$ foi realizada em vasos com $5 \mathrm{~kg}$ de solo, semeando-se oito sementes e mantendo-se três plantas por vaso após o desbaste. Utilizou-se a dose de $300 \mathrm{mg}$ por vaso de ${ }^{15} \mathrm{~N}$-uréia, enriquecida em $10 \%$ de átomos de ${ }^{15} \mathrm{~N}$ em excesso, parcelada de aplicações, 16, 30 e 48 dias após a emergência (DAE). Simultaneamente, também foram cultivados milheto e crotalária com a aplicação da mesma dose de uréia comercial (não enriquecida em ${ }^{15} \mathrm{~N}$ ), com a finalidade de produzir material com a abundância natural de ${ }^{15} \mathrm{~N}(0,366 \%)$. A colheita da crotalária e milheto foi realizada aos 70 DAE, e o material separado em raízes e parte aérea, lavado e seco a $60{ }^{\circ} \mathrm{C}$ em estufas por $72 \mathrm{~h}$. Após a secagem, o material foi fragmentado em pedaços de aproximadamente $0,02 \mathrm{~m}$. As raízes foram misturadas ao solo e a parte aérea adicionadas sobre a superfície, dez dias antes da semeadura do milho.

A produção de milho para a obtenção de palha com marcação isotópica foi realizada em condições de campo. Essa prática é recomendável, considerando o fato de em casa de vegetação geralmente ocorrer baixa homogeneidade no desenvolvimento de espiga, o que compromete principalmente a quantidade e a proporção de palha da espiga, sabugo e cabelo, em relação às outras partes da planta. A marcação isotópica foi realizada mediante a aplicação da dose de $40 \mathrm{~kg} \mathrm{ha}^{-1}$ de ${ }^{15} \mathrm{~N}$-uréia enriquecida em $10 \%$ de átomos de ${ }^{15} \mathrm{~N}$ em excesso, parcelada em três aplicações, aos 15, 30 e 45 DAE. Após a colheita do 
milho, a palha foi pesada e a parte destinada ao ensaio de casa de vegetação recebeu os mesmos procedimentos descritos anteriormente para os adubos verdes.

Para o experimento de campo, a palha de milho foi fragmentada em pedaços de tamanhos semelhantes aos promovidos pela colheita mecânica dos grãos e, em seguida, adicionados sobre a superfície do solo, numa quantidade de $7,35 \mathrm{Mg} \mathrm{ha}^{-1}$ (56 kg ha-1 de N-palha de milho). A área foi deixada em pousio por seis meses e cultivada novamente com milho sob SPD. O manejo do solo e da cultura do milho foi semelhante ao descrito em Silva et al. (2006b).

No cultivo do milho em casa de vegetação, utilizaram-se vasos com $5 \mathrm{~kg}$ de solo dispostos num delineamento experimental inteiramente casualizado com seis tratamentos e quatro repetições, compreendendo: $\mathrm{T}_{1}=$ palha de milho- ${ }^{15} \mathrm{~N}$ (80 $\mathrm{mg} \mathrm{kg}^{-1}$ de solo); $\mathrm{T}_{2}=$ raiz de milheto- ${ }^{15} \mathrm{~N}$ (30 mg kg-1 de $\mathrm{N}$ no solo); $\mathrm{T}_{3}=$ parte aérea de milheto${ }^{15} \mathrm{~N}$ (80 $\mathrm{mg} \mathrm{kg}^{-1}$ de $\mathrm{N}$ no solo); $\mathrm{T}_{4}=$ raiz de crotalária${ }^{15} \mathrm{~N}$ (30 $\mathrm{mg} \mathrm{kg}^{-1}$ de $\mathrm{N}$ no solo); $\mathrm{T}_{5}=$ parte aérea de crotalária- ${ }^{15} \mathrm{~N}$ (80 $\mathrm{mg} \mathrm{kg}{ }^{-1}$ de $\mathrm{N}$ no solo); e $\mathrm{T}_{6}=$ tratamento sem adição de fonte orgânica de N. As quantidades de resíduos vegetais adicionadas aos vasos compreenderam 52,6 g (400 mg de N); $20 \mathrm{~g}$ (150 mg de N); $43 \mathrm{~g}$ (400 mg de N); 12,5 g (150 mg de N) e $23 \mathrm{~g}$ (400 $\mathrm{mg}$ de $\mathrm{N}$ ), respectivamente, para o $\mathrm{T}_{1}, \mathrm{~T}_{2}, \mathrm{~T}_{3}, \mathrm{~T}_{4}$ e $\mathrm{T}_{5}$. Para os tratamentos que receberam raiz marcada com ${ }^{15} \mathrm{~N}$, adicionou-se parte aérea sem marcação isotópica na mesma quantidade que naqueles que receberam parte aérea marcada, e viceversa. As raízes foram incorporadas ao solo e a parte aérea adicionada sobre a superfície.

Foram colocadas para germinar três sementes por vaso de um híbrido simples (Pioneer 30F80), deixandose uma planta após desbaste, realizado aos 5 DAE. $\mathrm{Na}$ semeadura, foi adicionado o equivalente a 30,90 e $50 \mathrm{~kg} \mathrm{ha}^{-1}$, respectivamente, de $\mathrm{N}, \mathrm{P}_{2} \mathrm{O}_{5}$ e $\mathrm{K}_{2} \mathrm{O}$, seguindo-se recomendação descrita em Raij et al. (1996). A adubação nitrogenada de cobertura foi equivalente à dose de $100 \mathrm{~kg} \mathrm{ha}^{-1}$ de $\mathrm{N}$ e realizada aos 20 DAE, quando as plantas apresentavam quatro folhas expandidas. As plantas foram irrigadas diariamente, mantendo-se a umidade do solo em torno de $60 \%$ da capacidade de campo.

A colheita do milho foi realizada aos 120 DAE, mediante corte das plantas rente à superfície do solo, sendo o material seco em estufa a $65^{\circ} \mathrm{C}$ por $72 \mathrm{~h}$ e obtida massa do material seco total.

Nas amostras dos adubos verdes (parte aérea e raízes) e da palha do milho, após a secagem e moagem, foram determinados os teores de N, P, K, $\mathrm{Ca}, \mathrm{Mg}, \mathrm{S}, \mathrm{Cu}, \mathrm{Fe}, \mathrm{Mn}$ e $\mathrm{Zn}$, segundo método descrito em Malavolta et al. (1997). A relação $\mathrm{C} / \mathrm{N}$ foi determinada por meio do método de combustão via seca da amostra a $1400{ }^{\circ} \mathrm{C}$, por meio do aparelho LECO C/N.
$\mathrm{O}$ teor de $\mathrm{N}$ total e abundância de ${ }^{15} \mathrm{~N}$ nas amostras dos resíduos vegetais dos adubos verdes, da planta de milho, no experimento de vaso, e da palha e grãos de milho, no experimento de campo, foram determinados em espectrômetro de massa, com analisador automático de $\mathrm{N}$, conforme método de Barrie \& Prosser (1996). A seqüência de cálculos para determinar o aproveitamento do $\mathrm{N}$ pelo milho foi conforme descrito em Silva et al. (2006a).

Os dados foram submetidos à análise de variância com a aplicação do teste $\mathrm{F}$ e comparação das médias pelo teste de Tukey a $5 \%$, utilizando o programa estatístico SAS (2001).

\section{RESULTADOS E DISCUSSÃO}

A produção de matéria seca (MS) de parte aérea da crotalária foi maior que a do milheto (Quadro 1). Já a de raízes foi semelhante para as duas espécies, correspondendo, aproximadamente a $20 \%$ da MS total da planta. Também, o teor de $\mathrm{N}$ do sistema radicular foi menor que o da parte aérea de ambas as espécies, demonstrando ser esta o principal dreno para o acúmulo desse nutriente. Da mesma forma, a concentração de ${ }^{15} \mathrm{~N}$ também foi superior na parte aérea dos adubos verdes, possivelmente pelo fato de a alta solubilidade da uréia favorecer a rápida disponibilidade e absorção do $\mathrm{N}$ e, conseqüentemente, sua translocação e acúmulo na parte aérea.

A palha de milho apresentou menor teor de $\mathrm{N}$ e menor concentração de ${ }^{15} \mathrm{~N}$ (Quadro 1), o que provavelmente, em parte, foi devido à maior produção MS por planta (em média 118 g planta $^{-1}$ ) comparada à dos adubos verdes, promovendo, assim, diluição do ${ }^{15} \mathrm{~N}$. Além disso, o milho foi marcado em condições de campo, e o $\mathrm{N}$ aplicado nestas condições encontra-se mais susceptível a perdas do que em condições de vaso, onde o sistema radicular das plantas permanece confinado e explora todo o volume de solo (Scivittaro et al., 2000). O alto enriquecimento relativo, superior a 2,3 e $4,0 \%$ em átomos de ${ }^{15} \mathrm{~N}$, respectivamente, na palha de milho e de adubos verdes é suficiente para o estudo da dinâmica e aproveitamento do N no sistema solo-planta, o que, segundo Ambrosano et al. (2003), valores acima de $2 \%$ já são satisfatórios. Comparando os dois adubos verdes, verifica-se que o milheto apresentou tanto na parte aérea quanto no sistema radicular maior enriquecimento em ${ }^{15} \mathrm{~N}$ do que a crotalária. Tal fato é comum de ocorrer, em razão da associação simbiótica entre leguminosas com bactérias do gênero rizóbio, que promovem a fixação biológica de $\mathrm{N}_{2}$ diluindo, assim, o ${ }^{15} \mathrm{~N}$ (Ambrosano et al., 2003; Silva et al., 2006a).

Observou-se que os resíduos vegetais, sobretudo dos adubos verdes, apresentaram consideráveis teores de outros nutrientes, sendo os teores de $\mathrm{S}$; $\mathrm{Cu}, \mathrm{Mn}$ e $\mathrm{Zn}$ superiores no sistema radicular (Quadro 2). 
Considerando a produção de MS, a parte aérea dos adubos verdes acumulou maior quantidade de macro e micronutrientes, com destaque para o K, que apresentou alto teor. Tal fato assume relevância no manejo desse nutriente, graças à sua rápida liberação dos resíduos vegetais, por não fazer parte de nenhum composto celular (Malavolta et al., 1997). Ao contrário do $\mathrm{N}$ e da maioria dos demais nutrientes, que normalmente seguem um padrão gradual, acompanhando a taxa de mineralização. Embora alguns nutrientes apresentem menores teores na palha de milho do que nos adubos verdes, a quantidade de palha produzida, geralmente superior a $6 \mathrm{Mg} \mathrm{ha}^{-1}$ (Wisniewski \& Holtz, 1997; Guimarães et al., 2006), confere à cultura grande potencial de retorno de nutrientes ao solo, a exemplo do verificado por Guimarães et al. (2006), de 67, 26, $153,42,35$ e $11 \mathrm{~kg} \mathrm{ha}^{-1}$, respectivamente, de N, P, $\mathrm{K}, \mathrm{Ca}, \mathrm{Mg}$ e $\mathrm{S}$.

A análise de variância evidenciou efeito significativo dos tratamentos sobre a produtividade de MS da planta de milho, conteúdo de $\mathrm{N}$ acumulado na planta (NA), quantidade de $\mathrm{N}$ na planta proveniente do resíduo vegetal (milheto, crotalária ou palha de milho) (QNPPRV) e aproveitamento do $\mathrm{N}$ do resíduo vegetal pela planta de milho (APROV).

Quadro 1. Produção de matéria seca, teor de $\mathrm{N}$ total, concentração de ${ }^{15} \mathrm{~N}$ e relação $\mathrm{C} / \mathrm{N}$ da parte aérea e do sistema radicular da crotalária e do milheto e da palha do milho, aplicados ao solo como fonte de $\mathrm{N}$ para a cultura do milho

\begin{tabular}{|c|c|c|c|c|}
\hline Resíduo vegetal & Matéria seca & Nitrogênio total & Concentração de ${ }^{15} \mathrm{~N}$ & Relação C/N \\
\hline & g vaso-1 & $\mathrm{g} \mathrm{kg}^{-1}$ & $\%$ de átomos & \\
\hline \multicolumn{5}{|c|}{ Parte aérea } \\
\hline Crotalária & $26,1 \mathrm{a}^{(1)}$ & $17,4 \mathrm{a}$ & $5,033 \mathrm{~b}$ & $30 / 1 \mathrm{c}$ \\
\hline Milheto & $22,7 \mathrm{~b}$ & $9,2 \mathrm{~b}$ & $6,422 \mathrm{a}$ & $51 / 1 \mathrm{~b}$ \\
\hline Palha de milho & - & $7,6 \mathrm{c}$ & $2,312 \mathrm{c}$ & $69 / 1 \mathrm{a}$ \\
\hline \multicolumn{5}{|c|}{ Sistema radicular } \\
\hline Crotalária & $6,5 \mathrm{a}$ & $12,0 \mathrm{a}$ & $4,068 \mathrm{~b}$ & $33 / 1 \mathrm{~b}$ \\
\hline Milheto & $6,2 \mathrm{a}$ & $7,5 \mathrm{~b}$ & $5,347 \mathrm{a}$ & $58 / 1$ a \\
\hline
\end{tabular}

(1) Médias seguidas por letras iguais, na coluna, dentro de parte aérea ou dentro de sistema radicular, não diferem significativamente entre si pelo teste de Tukey a $5 \%$.

Quadro 2. Teores médios de P, K, Ca, Mg, S, Cu, Fe, Mn e Zn na parte aérea e no sistema radicular da crotalária e do milheto e na palha de milho, aplicados ao solo como fonte de $\mathrm{N}$ para a cultura do milho

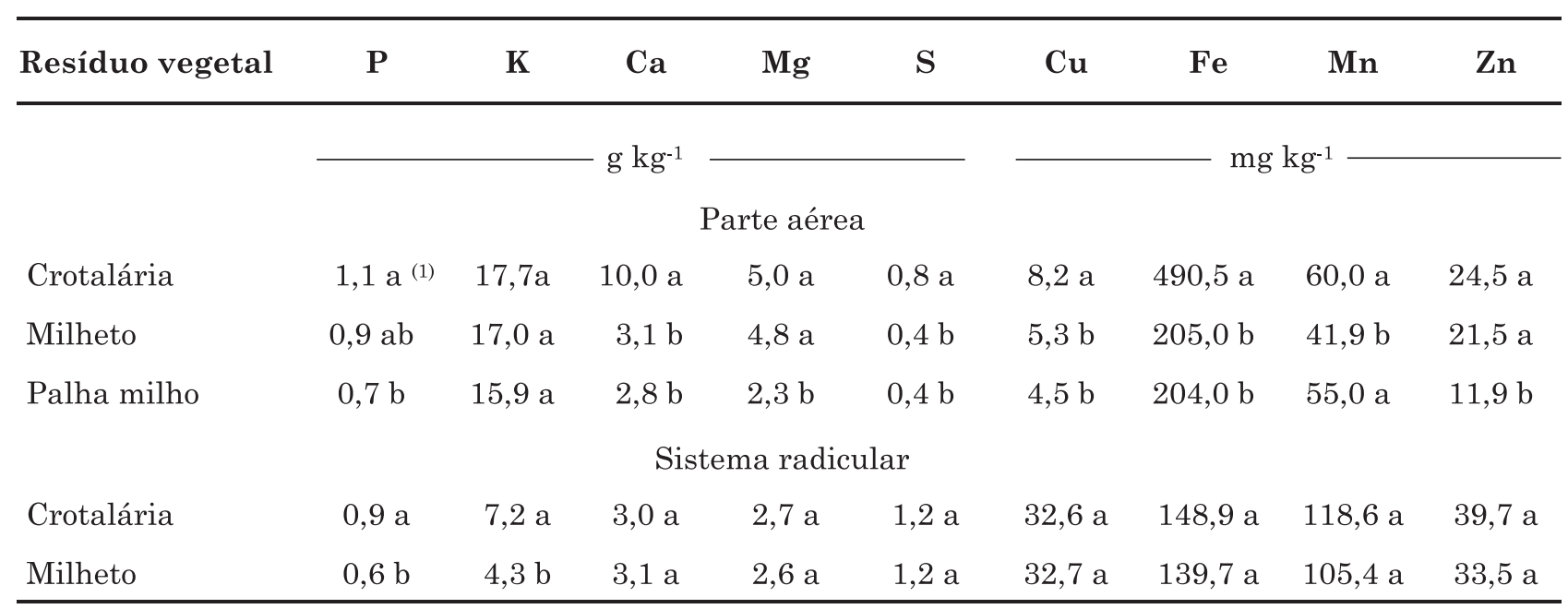

(1) Médias seguidas por letras iguais, na coluna, dentro de parte aérea ou dentro de sistema radicular, não diferem significativamente entre si pelo teste de Tukey a $5 \%$. 
$\mathrm{O}$ teor de $\mathrm{N}$ total na planta de milho não foi influenciado pelos tratamentos (Quadro 3), ao contrário da quantidade de $\mathrm{N}$ acumulado, que foi proporcional à produção de MS, indicando que os tratamentos condicionaram a absorção e acúmulo do $\mathrm{N}$ pela planta. A crotalária proporcionou ao milho maior produção de MS comparada ao milheto, que não diferiu da palha de milho e do tratamento sem a aplicação de resíduo vegetal. $\mathrm{O}$ conteúdo de $\mathrm{N}$ acumulado também foi superior no milho cultivado sobre resíduos de crotalária comparado ao dos demais tratamentos, que foram semelhantes entre si, o que sugere que essa leguminosa promoveu efeito sinérgico à absorção de $\mathrm{N}$ pelo milho. Tal fato, provavelmente, deveu-se à menor relação C/ $\mathrm{N}$ (Quadro 1), que correspondeu a menos da metade que a da palha de milho e também inferior à do milheto, tanto do sistema radicular quanto da parte aérea. Desse modo, aliada à grande presença de compostos solúveis, favoreceu a maior e a mais rápida decomposição/ mineralização do $\mathrm{N}$ pelos microrganismos quimiorganotróficos, estimulando a maior e à mais regular absorção desse nutriente pelo milho, sobretudo na fase vegetativa, quando é definida a produção potencial da cultura (Aita et al., 2001; Amado et al., 2002; Silva et al., 2006a). Ao contrário do milheto e, principalmente da palha de milho, cujas altas relações $\mathrm{C} / \mathrm{N}$ podem ter condicionado a reimobilização do $\mathrm{N}$ mineralizado e, ou, imobilização do $\mathrm{N}$ nativo do solo e do $\mathrm{N}$ do fertilizante mineral, como verificado em outros estudos (Power et al., 1986; Lara Cabezas et al., 2004; Silva et al., 2006a). Semelhantemente Sampaio \& Salcedo (1993), em condições de casa de vegetação, também verificaram que praticamente nada do $\mathrm{N}$ da palha do milho marcada com ${ }^{15} \mathrm{~N}$ foi recuperado pelo milheto, em razão da lenta mineralização e reimobilização de $\mathrm{N}$.

As quantidades de $\mathrm{N}$ no milho provenientes da parte aérea do milheto ou crotalária foram superiores às provenientes do sistema radicular (Quadro 4); embora esse fato, certamente, tenha sido em virtude das distintas quantidades de N-resíduo aplicadas $(30 \mathrm{mg}$ $\mathrm{kg}^{-1}$ de N-raiz no solo versus $80 \mathrm{mg} \mathrm{kg}^{-1} \mathrm{~N}$-parte aérea no solo); uma vez que, no caso do milheto, quando se considera o aproveitamento do $\mathrm{N}$, que é relativo à dose aplicada, não houve diferença entre raiz ou parte aérea. Para a crotalária, o aproveitamento pelo milho do $\mathrm{N}$ da parte aérea foi superior ao do $\mathrm{N}$ da raiz, possivelmente pela maior quantidade de compostos solúveis na parte aérea. Também, outras características dos resíduos vegetais como o teor de lignina, de polifenóis e a relação lignina/N e polifenóis/N, provavelmente influenciaram a taxa de decomposição/mineralização do N, a exemplo do verificado em outros estudos (Palm \& Sanchez, 1991; Sampaio \& Salcedo, 1993; Wisniewski \& Holtz, 1997; Silva et al., 2006a).

Considerando a dose total de N-resíduo vegetal aplicada (400 mg vaso ${ }^{-1}$ de $\mathrm{N}$ na parte aérea $+150 \mathrm{mg}$ vaso $^{-1}$ de N nas raízes) (Quadro 4), a QNPPRV e o aproveitamento do $\mathrm{N}$ pelo milho do $\mathrm{N}$ da crotalária foi mais do que o triplo em relação ao $\mathrm{N}$ do milheto. Entretanto, mais de $75 \%$ do $\mathrm{N}$ da crotalária e mais de $90 \%$ do $\mathrm{N}$ do milheto não foram absorvidos pelo milho, o que é um indicativo da decomposição incompleta dos resíduos durante o ciclo da cultura, principalmente daqueles da parte aérea, certamente favorecida pela sua não-incorporação ao solo (Wisniewski \& Holtz, 1997; Amado et al., 2002), o que ficou caracterizado visualmente. Outro fato comum, e que pode ter ocorrido, é o de parte do $\mathrm{N}$ mineralizado ter interagido com o $\mathrm{N}$ do solo, passando para formas orgânicas. Resultados nesse sentido com adubos verdes marcados com ${ }^{15} \mathrm{~N}$, em que a maior proporção do N contido na MS teve como destino o solo foram verificados em outros estudos (Azam et al., 1985; Harris et al., 1994; Scivittaro et al., 2000). O aproveitamento de $20,33 \%$ para o $\mathrm{N}$ da crotalária e de $5,63 \%$ para o $\mathrm{N}$ do milheto mostrou-se superior e próximo ao dos valores obtidos, em condições de campo, por Silva et al. (2006a), de $13 \%$, para o N da crotalária, e de $6 \%$, para o $\mathrm{N}$ do milheto.

Quadro 3. Produção de matéria seca (MS), teor e conteúdo de N-total e teor de ${ }^{15} \mathrm{~N}$ na planta de milho, cultivada em casa de vegetação, após a aplicação de crotalária, milheto (parte aérea e raiz) ou palha de milho como fonte de nitrogênio

\begin{tabular}{llllc}
\hline \multirow{2}{*}{ Tratamento } & MS & \multicolumn{2}{c}{ N-total } & Concentração ${ }^{15} \mathbf{N}$ \\
\cline { 3 - 4 } & & Teor & Conteúdo & \\
\hline & g vaso $^{-1}$ & $\mathrm{mg} \mathrm{g}^{-1}$ & mg vaso-1 $^{-1}$ & 0,558 \\
Parte aérea crotalária (PAC) & 184,7 & 12,5 & 2317,8 & 0,419 \\
Raiz crotalária (RC) & 160,3 & 12,4 & 1988,9 & - \\
Planta inteira PAC + RC & $172,5 \mathrm{a}$ & $12,5 \mathrm{a}$ & $2153,4 \mathrm{a}$ & 0,453 \\
Parte aérea milheto (PAM) & 140,2 & 10,9 & 1512,6 & 0,407 \\
Raiz milheto (RM) & 133,5 & 11,0 & 1470,8 & - \\
Planta inteira PAM + RM & $136,9 \mathrm{~b}$ & $10,9 \mathrm{a}$ & $1491,7 \mathrm{~b}$ & 0,382 \\
Palha milho & $129,1 \mathrm{~b}$ & $10,8 \mathrm{a}$ & $1393,0 \mathrm{~b}$ & - \\
Solo sem resíduo & $117,9 \mathrm{~b}$ & $11,3 \mathrm{a}$ & $1325,5 \mathrm{~b}$ & \\
\hline
\end{tabular}

(1) Médias seguidas por letras iguais, na coluna, não diferem significativamente entre si pelo teste de Tukey a 5 \%). 
Independentemente do resíduo vegetal, o menor aproveitamento do $\mathrm{N}$ pelo milho foi para o da palha de milho, certamente por sua mais alta relação $\mathrm{C} / \mathrm{N}$ (69/ 1) associada ao alto teor de lignina, a exemplo do verificado por Wisniewski \& Holtz (1997), utilizando a técnica de sacos de náilon, em que a taxa de decomposição de palha de milho foi muito inferior à da aveia preta. No entanto, deve-se considerar que, no presente estudo, os valores estão subestimados, por não ter sido contabilizado o $\mathrm{N}$ fornecido pelo sistema radicular do milho, o qual também permanece no solo após a colheita. Em adição, em todos os tratamentos, foi mensurado apenas o $\mathrm{N}$ contido na parte aérea da planta de milho, representando, portanto, uma subestimativa do total aproveitado. Pesquisa realizada por Coelho et al. (1991) demonstrou que o sistema radicular do milho representou $5 \%$ da MS total da planta e $4 \%$ do $\mathrm{N}$ total acumulado. Possivelmente, esse fato assume relevância para o aproveitamento do
$\mathrm{N}$ dos adubos verdes, uma vez que existem relatos de que grande parte do $\mathrm{N}$ absorvido dessas fontes fica retida nas raízes do milho (Azam et al., 1985).

A produtividade de palha, no experimento de campo, foi superior à de grãos (Quadro 5), conferindo um índice de colheita (fração de grãos em relação à de MS total da parte aérea) de 0,47 . Já a quantidade de $\mathrm{N}$ originária dos restos culturais do milho acumulada nos grãos foi mais do que o dobro da acumulada no restante da parte aérea, condicionando, assim, maior aproveitamento.

$\mathrm{O}$ aproveitamento do $\mathrm{N}$ da palha de milho pelo milho cultivado no campo (Quadro 5) foi superior ao cultivado em casa de vegetação (Quadro 4), o que possivelmente deveu-se à maior permanência dos resíduos no campo antes da semeadura do milho (seis meses) em relação à adição desses aos vasos (10 dias antes da semeadura). Nesse sentido, Wisniewski \&

Quadro 4. Percentagem de nitrogênio na planta de milho proveniente do resíduo vegetal (NPPRV), quantidade de nitrogênio na planta de milho proveniente do resíduo vegetal (QNPPRV), aproveitamento do nitrogênio do resíduo vegetal (APROV) pela planta de milho, em casa de vegetação, após a aplicação de crotalária, milheto (parte aérea e raiz) ou palha de milho como fonte de nitrogênio

\begin{tabular}{lllc}
\multicolumn{1}{c}{ Tratamento } & NPPRV & QNPPRV & APROV \\
\hline & $\%$ & $\mathrm{mg} \mathrm{vaso}^{-1}$ & $\%$ \\
Parte aérea crotalária (PAC) & $3,77 \mathrm{a}^{(1)}$ & $87,10 \mathrm{a}$ & $21,74 \mathrm{a}$ \\
Raiz crotalária (RC) & $1,25 \mathrm{~b}$ & $24,70 \mathrm{~b}$ & $16,47 \mathrm{~b}$ \\
Planta inteira PAC + RC & - & $111,80 \mathrm{~A}$ & $20,33 \mathrm{~A}$ \\
Parte aérea milheto (PAM) & $1,33 \mathrm{~b}$ & $20,24 \mathrm{~b}$ & $5,06 \mathrm{c}$ \\
Raiz milheto (RM) & $0,73 \mathrm{~cd}$ & $10,74 \mathrm{~cd}$ & $7,16 \mathrm{c}$ \\
Planta inteira PAM + RM & - & $30,98 \mathrm{~B}$ & $5,63 \mathrm{~B}$ \\
Palha milho & $0,61 \mathrm{~d}$ & $8,27 \mathrm{~d}$ & $2,07 \mathrm{~d}$ \\
\hline
\end{tabular}

(1) Médias seguidas por letras iguais maiúsculas ou minúsculas, na coluna, não diferem significativamente entre si pelo teste de Tukey a $5 \%$.

Quadro 5. Produtividade de matéria seca de parte aérea (palha) e grãos de milho, teor de N-total, concentração de ${ }^{15} \mathrm{~N}$, percentagem de nitrogênio na planta proveniente da palha de milho (NPPRV), quantidade de nitrogênio na planta proveniente da palha de milho (QNPPRV) e aproveitamento pelo milho do nitrogênio da palha de milho (APROV), em condições de campo

\begin{tabular}{|c|c|c|c|c|c|}
\hline Matéria seca & Teor de $\mathbf{N}$ & Conc. de ${ }^{15} \mathrm{~N}$ & NPPRV & QNPPRV & APROV \\
\hline $\mathrm{Mg} \mathrm{ha}^{-1}$ & $\mathrm{~g} \mathrm{~kg}^{-1}$ & $\%$ de átomos & $\%$ & $\mathrm{~kg} \mathrm{ha}^{-1}$ & $\%$ \\
\hline \multicolumn{6}{|c|}{ Parte aérea } \\
\hline $6,38 \mathrm{a}^{(1)}$ & $6,5 \mathrm{~b}$ & $0,410 \mathrm{a}$ & $1,64 \mathrm{a}$ & $0,68 \mathrm{~b}$ & $1,21 \mathrm{~b}$ \\
\hline \multicolumn{6}{|c|}{ Grãos } \\
\hline $5,67 \mathrm{~b}$ & $14,6 \mathrm{a}$ & $0,412 \mathrm{a}$ & $1,85 \mathrm{a}$ & $1,52 \mathrm{a}$ & $2,90 \mathrm{a}$ \\
\hline
\end{tabular}

(1) Médias seguidas por letras iguais, na coluna, não diferem significativamente entre si pelo teste de Tukey a $5 \%$. 
Holtz (1997) estimaram que $51 \%$ do $\mathrm{N}$ da palha do milho, equivalente a $48 \mathrm{~kg} \mathrm{ha}^{-1} \mathrm{de} \mathrm{N}$, foi mineralizado no período de 149 dias após sua adição sobre a superfície do solo. Os resultados do presente estudo diferem dos obtidos por Power et al. (1986), em que o $\mathrm{N}$ da palha do milho não foi aproveitado pelo milho cultivado em sucessão. Tal fato, provavelmente, está relacionado com as distintas condições edafoclimáticas, sobretudo de temperatura, que é bastante elevada na região do presente estudo, favorecendo, portanto, a atividade microbiana com relativa rápida decomposição/ mineralização do $\mathrm{N}$ dos resíduos vegetais.

De maneira geral, a maior fração do $\mathrm{N}$ contido nos resíduos vegetais não foi absorvida pelo milho, podendo pressupor que a maior parte desse nutriente permaneceu no solo, predominantemente sob formas orgânicas, o que coincide com o relatado em outros estudos (Azam et al., 1985; Sampaio \& Salcedo, 1993; Harris et al., 1994; Scivittaro et al., 2000; Amado et al., 2002). Esse aspecto indica a necessidade de, nestas condições, enfatizar sistemas de manejo do solo e de culturas que promovam a reciclagem do $\mathrm{N}$ em sua biomassa, evitando perdas para camadas fora do alcance das raízes das plantas, o que é indesejável econômica e ambientalmente.

\section{CONCLUSÕES}

1. A crotalária proporcionou maior absorção de $\mathrm{N}$ e produtividade de matéria seca ao milho.

2. O aproveitamento do $\mathrm{N}$ da parte aérea da crotalária pelo milho foi superior ao do $\mathrm{N}$ do sistema radicular e semelhante entre ambas as partes, para 0 $\mathrm{N}$ do milheto.

3. A absorção pelo milho do $\mathrm{N}$ mineralizado dos restos culturais de milho, no campo, foi de $4,1 \%$ da quantidade inicial.

4. $\mathrm{O}$ aproveitamento do $\mathrm{N}$ dos resíduos vegetais pelo milho foi na ordem: crotalária $>$ milheto $>$ palha de milho.

5. A maior parte do $\mathrm{N}$ dos resíduos vegetais não foi absorvida pelo milho.

\section{AGRADECIMENTOS}

À Fundação de Amparo à Pesquisa do Estado de São Paulo (FAPESP), pela concessão de bolsa e auxilio financeiro, e à International Atomic Energy Agency (IAEA), pela concessão de ${ }^{15} \mathrm{~N}$.

\section{LITERATURA CITADA}

AITA, C.; BASSO, C.J.; CERETA, C.J.; GONÇALVES, C.N. \& ROS, C.O. Plantas de cobertura do solo como fonte de nitrogênio ao milho. R. Bras. Ci. Solo, 25:157-165, 2001.
AMADO, T.J.C.; MIELNICZUK, J. \& AITA, C. Recomendação de adubação nitrogenada para o milho no RS e SC adaptada ao uso de culturas de cobertura do solo, sob sistema plantio direto. R. Bras. Ci. Solo, 26:241-248, 2002.

AMBROSANO, E.J.; TRIVELIN, P.C.O.; CANTARELLA, H.; ROSSETTO, R.; MURAOKA, T.; BENDASSOLLI, J.A.; AMBROSANO, G.M.B.; TAMISO, L.G.; VIEIRA, F.C. \& PRADA NETO, I. Nitrogen-15 labeling of Crotalaria juncea green manure. Sci. Agric., 60:181-184, 2003.

AZAM, F.; MALIK, K.A. \& SAJJAD, M.I. Transformations in soil and availability to plants of ${ }^{15} \mathrm{~N}$ applied as inorganic fertilizer and legume residues. Plant Soil, 86:3-13, 1985.

BARRIE, A. \& PROSSER, S.J. Automated analysis of lightelement stable isotopes by isotope ratio mass spectrometry. In: BOUTTON, T.W. \& YAMASAKI, S., eds. Mass spectrometry of soils. New York, Marcel Dekker, 1996. p.1-46.

CANTARELLA, H. \& DUARTE, A.P. Manejo da fertilidade do solo para a cultura do milho. In: GALVÃO, J.C.C. \& MIRANDA, G.V. Tecnologia de produção de milho. Viçosa, MG, Universidade Federal de Viçosa, 2004. p.139-182.

COELHO, A.M.; FRANÇA, G.C.; BAHIA, A.F.C. \& GUEDES, G.A. Balanço de nitrogênio ${ }^{15} \mathrm{~N}$ em Latossolo VermelhoEscuro, sob vegetação de cerrado, cultivado com milho. R. Bras. Ci. Solo, 95:187-193, 1991.

EMPRESA BRASILEIRA DE PESQUISA AGROPECUÁRIA . EMBRAPA. Sistema brasileiro de classificação de solos. Brasília, Serviço de Produção de informações, Rio de Janeiro, 1999. 412p.

GUIMARÃES, G.L.; BUZETTI, S.; LAZARINI, E.; SÁ, M.E.; ARF, O. \& ANDRADE, J.A.C. Efeito de culturas de verão e opções de inverno na cultura do milho e no solo na implantação do plantio direto. Acta Sci., 28:471-477, 2006.

HARRIS, G.H.; HESTERMAN, O.B.; PAUL, E.A.; PETERS, S. \& E.JANKE, R.R. Fate of legume and fertilizer nitrogen15 in a long term cropping systems experiment. Agron. J., 86:910-915, 1994

LARA CABEZAS, W.R.L.; ALVES, B.J.R.; URQUIAGA, S. \& SANTANA, D.G. Influência da cultura antecessora e da adubação nitrogenada na produtividade de milho em sistema plantio direto e solo preparado. Ci. Rural, 34:10051013, 2004.

MALAVOLTA, E.; VITTI, G.C. \& OLIVEIRA, S.A. Avaliação do estado nutricional das plantas: Princípios e aplicações. 2. ed. Piracicaba, POTAFOS, 1997. 319p.

PALM, C.A. \& SANCHEZ, P.A. Nitrogen release from the leaves of some tropical legumes as affected by their lignin and polyphenolic contents. Soil Biol. Biochem., 23:83-88, 1991.

PERIN, A.; SANTOS, R.H.S.; URQUIAGA, S.C.; GUERRA, J.G.M. \& CECON, P.R. Produção de fitomassa, acúmulo de nutrientes e fixação biológica de nitrogênio por adubos verdes em cultivo isolado e consorciado. Pesq. Agropec. Bras., 39:35-40, 2004.

POWER, J.F.; DORAN, J.W. \& WILHELM, W.W. Uptake of nitrogen from soil, fertilizer and crop residues by no till corn and soybean. Soil Sci. Soc. Am. J., 50:137-142, 1986. 
RAIJ, B. van, ANDRADE, J.C., CANTARELLA, H. \& QUAGGIO, J.A. Análise química para avaliação da fertilidade de solos tropicais. Campinas, Instituto Agronômico, 2001. 285p.

RAIJ, B. van.; CANTARELLA, H.; QUAGGIO, J.A. \& FURLANI, A.M.C. Recomendações de adubação e calagem para o Estado de São Paulo. 2.ed. Campinas, Instituto Agronômico de Campinas, 1996. 285p. (Boletim Técnico, 100)

SAMPAIO, E.V.S.B. \& SALCEDO, L.H. Mineralização e absorção por milheto do nitrogênio do solo, da palha de milho $\left({ }^{15} \mathrm{~N}\right)$ e da uréia $\left({ }^{15} \mathrm{~N}\right)$. R. Bras. Ci. Solo, 17:423-429, 1993.

SAS Institue. SAS/STAT user's guide. Version 8.2. Cary, 2001. $943 p$.

SCIVITTARO, W.B.; MURAOKA, T.; BOARETTO, A.E. \& TRIVELIN, P.C.O. Utilização de nitrogênio de adubos verdes e mineral pelo milho. R. Bras. Ci. Solo, 24:917926, 2000.
SILVA, E.C.; MURAOKA, T.; BUZETTI, S.; GUIMARÃES, G.L.; TRIVELIN, P.C.O. \& VELOSO, M.E.C. Utilização do nitrogênio $\left({ }^{15} \mathrm{~N}\right)$ residual de plantas de cobertura de solo e da uréia pela cultura do milho. R. Bras. Ci. Solo, 30:966974, 2006b.

SILVA, E.C.; MURAOKA, T.; BUZETTI, S.; VELOSO, M.E.C. \& TRIVELIN, P.C.O. Aproveitamento do nitrogênio $\left({ }^{15} \mathrm{~N}\right)$ da crotalária e do milheto pelo milho sob plantio direto em Latossolo Vermelho de Cerrado. Ci. Rural, 36:739$746,2006 a$.

SOUSA, D.M.G. \& LOBATO, E. Adubação com nitrogênio. In: SOUSA, D.M.G. \& LOBATO, E., eds. Cerrado: Correção do solo e adubação. 2.ed. Planaltina, Embrapa Cerrados, 2004. p.129-144.

WISNIEWSKI, C. \& HOLTZ, G.P. Decomposição da palhada e liberação de nitrogênio e fósforo numa rotação aveia soja sob plantio direto. Pesq. Agropec. Bras., 32:1191-1197, 1997. 
